\title{
The Photochemistry and Stereochemical Control of Clay-Intercalated Compounds
}

\author{
Tetsuya Shichi*, ${ }^{\dagger}$ and Katsuhiko Takagi ${ }^{\dagger, \dagger \dagger}$ \\ ${ }^{\dagger}$ Department of Crystalline Materials Science, Graduate School of Engineering, \\ Nago ya University, \\ ${ }^{+}$CREST, Japan Science and Technology (JST)
}

Received July 12, 2002

\begin{abstract}
This article surveys investigations on stereospecific organic photoreactions utilizing well-organized aggregated structures of molecules formed in the interlayer spaces of inorganic layered host compounds. In the beginning sections, the chemical compositions and structural features of the layered hosts and their unique adsorption properties are described, as well as the aggregated structures of the guest molecules. The later sections describe various organic photoreactions, including [2+2] photocycloadditions, photopolymerization and the photopinacolization of aromatic olefins and/or aromatic ketones, while the stereochemistry of the photoreactions is discussed in relation to the aggregated structures of the guest molecules.
\end{abstract}

\section{Introduction}

Inorganic layered materials are the most fundamental and useful materials known to mankind. Since prehistoric times, humans have made use of clays and clay minerals as the raw materials for china and porcelain. In recent times, these materials are used for all kinds of industrial and agricultural purposes, and their usage can be said to be innumerable; e.g., fine ceramics, coating materials for papers and resinous sheets, as well as additives for reinforced plastics and soil conditioners, just to name a few. Most recently, they are receiving renewed interest from science and academia as well as industry for their unique and interesting properties, especially their capacity to adsorb not only inorganic but also organic materials, providing new and effective functional organic/inorganic hybrid materials. Investigations into their fundamental and molecular structure as well as their varied characteristic properties have revealed their great potential in the development of new devices and systems composed of functionalized organic and inorganic compounds. ${ }^{1-4}$

The present article aims to investigate and clarify the unique intercalation properties of clay minerals and related layered host materials as well as their characteristic photochemical reactions in such host-guest lamellae for design and development of novel approaches in selective and stereospecific organic photochemistry.

\section{Structures of the Layered Host Compounds}

\subsection{Cation-Exchange Clay}

Clay minerals possess a layered structure and are typically suspended in aqueous solutions as fine particles having an average diameter of about $2 \mu \mathrm{m} .{ }^{5}$ Generally, they have the potential for ion-exchange, being able to accommodate ionic and even nonionic foreign organic molecules into their interlayers. Montmorillonite, a representative clay mineral, is composed of units made up of two silica tetrahedral sheets and an alumina octahedral sheet, as shown in Figure 1. Their intersheet layers include exchangeable metal ions (e.g., sodium ions), neutralizing the net negative charges which are gen- erated by the partial substitution of $\mathrm{Al}^{3+}$ with $\mathrm{Mg}^{2+}$ at the octahedral sites. These characteristics explain why montmorillonite tends to be easily suspended in water and to adsorb the cationic species. On the other hand, kaolinite possesses layers consisting of a 1:1 pair of octahedral and tetrahedral sheets; however, the capacity for ion-exchange is restricted since no swelling can be seen to occur, as shown in Table 1. Clay minerals are classified not only by the differences in their layered structures but also by the types of metals substituted, the amounts and kinds of exchangeable ions within the interlayers, and the impurities present. The intercalation properties of clay minerals as host materials can, therefore, be applied to construct organically modified layer surfaces in the clay minerals. With regard to the ability for ion exchange, clays such as smectite and vermiculite, having small amounts of anion charges in their layers, act as good acceptors and have a good swelling nature, while mica and kaolin, with their large ionic charges, do not swell and are thus unable to exchange ions.

The number of exchangeable ions within the clay minerals determines the amount of organic guest ions which can be

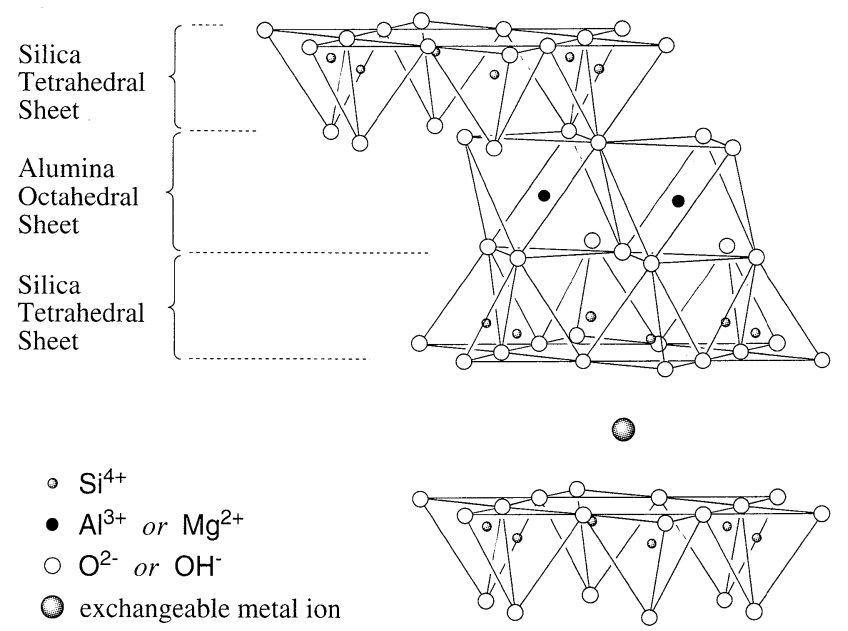

Figure 1. The laminating structure of montmorillonite clay. 
Table 1. Classification of clay minerals

\begin{tabular}{lll}
\hline clay & ideal composition & layer \\
& $\mathrm{M}_{\text {int }}\left(\mathrm{M}_{\mathrm{oct}}\right)\left(\mathrm{M}_{\mathrm{tetra}}\right) \mathrm{O}_{1}(\mathrm{OH})_{\mathrm{m}} \cdot \mathrm{nH}_{2} \mathrm{O}^{\mathrm{a}}$ & schematic \\
\end{tabular}

$1: 1$

KAOLINITE GROUP (charge density: 0 /unit)

$\begin{array}{ll}\text { kaolinite } & \left(\mathrm{Al}_{2}\right)\left(\mathrm{Si}_{2}\right) \mathrm{O}_{5}(\mathrm{OH})_{4} \\ \text { halloysite } & \left(\mathrm{Al}_{2}\right)\left(\mathrm{Si}_{2}\right) \mathrm{O}_{5}(\mathrm{OH})_{4} \cdot 2 \mathrm{H}_{2} \mathrm{O}\end{array}$

SERPENTINE GROUP (charge density: 0 /unit)

$$
\text { serpentine } \quad\left(\mathrm{Mg}_{6}\right)\left(\mathrm{Si}_{4}\right) \mathrm{O}_{10}(\mathrm{OH})_{8}
$$

$2: 1$

PYLOPHYLLITE GROUP (charge density: $~ 0$ /unit)

$$
\begin{array}{ll}
\text { pyrophyllite } & \left(\mathrm{Al}_{2}\right)\left(\mathrm{Si}_{4}\right) \mathrm{O}_{10}(\mathrm{OH})_{2} \\
\text { talc } & \left(\mathrm{Mg}_{3}\right)\left(\mathrm{Si}_{4}\right) \mathrm{O}_{10}(\mathrm{OH})_{2}
\end{array}
$$

SMECTITE GROUP (charge density: $\mathrm{x} \sim 0.2-0.6$ /unit)

$\begin{array}{ll}\text { montmorillonite } & \mathrm{M}_{\mathrm{x}}\left(\mathrm{Al}_{2-\mathrm{x}} \mathrm{Mg}_{\mathrm{x}}\right)\left(\mathrm{Si}_{4}\right) \mathrm{O}_{10}(\mathrm{OH})_{2} \cdot \mathrm{nH}_{2} \mathrm{O} \\ \text { beidellite } & \mathrm{M}_{\mathrm{x}}\left(\mathrm{Al}_{2}\right)\left(\mathrm{Si}_{4-\mathrm{x}} \mathrm{Al}_{\mathrm{x}}\right) \mathrm{O}_{10}(\mathrm{OH})_{2} \cdot \mathrm{nH}_{2} \mathrm{O} \\ \text { nontronite } & \mathrm{M}_{\mathrm{x}}\left(\mathrm{Fe}^{3+}{ }_{2}\right)\left(\mathrm{Si}_{4-\mathrm{x}} \mathrm{Al}_{\mathrm{x}}\right) \mathrm{O}_{10}(\mathrm{OH})_{2} \cdot \mathrm{nH}_{2} \mathrm{O} \\ \text { saponite } & \mathrm{M}_{\mathrm{x}}\left(\mathrm{Mg}_{3}\right)\left(\mathrm{Si}_{4-\mathrm{x}} \mathrm{Al}_{\mathrm{x}}\right) \mathrm{O}_{10}(\mathrm{OH})_{2} \cdot \mathrm{nH}_{2} \mathrm{O} \\ \text { hectorite } & \mathrm{M}_{\mathrm{x}}\left(\mathrm{Mg}_{3-\mathrm{x}} \mathrm{Li}_{\mathrm{x}}\right)\left(\mathrm{Si}_{4}\right) \mathrm{O}_{10}(\mathrm{OH})_{2} \cdot \mathrm{nH}_{2} \mathrm{O}\end{array}$

VERMICULITE GROUP (charge density: $\mathrm{x} \sim 0.6-0.9$ /unit)

dioctahedral vermiculite $\quad \mathrm{M}_{\mathrm{x}}\left(\mathrm{Al}_{2-\mathrm{y}} \mathrm{Fe}^{3+}{ }_{\mathrm{y}}\right)\left(\mathrm{Si}_{4-\mathrm{x}} \mathrm{Al}_{\mathrm{x}}\right) \mathrm{O}_{10}(\mathrm{OH})_{2} \cdot \mathrm{nH}_{2} \mathrm{O}$ trioctahedral vermiculite $\mathrm{M}_{\mathrm{x}}\left(\mathrm{Mg}_{3}\right)\left(\mathrm{Si}_{4-\mathrm{x}} \mathrm{Al}_{\mathrm{x}}\right) \mathrm{O}_{10}(\mathrm{OH})_{2} \cdot \mathrm{nH}_{2} \mathrm{O}$

MICA GROUP (charge density: $\mathrm{x} \sim 0.6-1$ /unit)

mica (muscovite)

illite

biotite

\section{CHLORITE GROUP}

cookeite

clinochlore

chamosite

CHANNEL TYPE

sepiolite

palygorskite

$$
\mathrm{K}\left(\mathrm{Al}_{2}\right)\left(\mathrm{Si}_{3} \mathrm{Al}\right) \mathrm{O}_{10}(\mathrm{OH})_{2}
$$$$
\mathrm{K}_{\mathrm{x}}\left(\mathrm{Al}_{2}\right)\left(\mathrm{Si}_{4-\mathrm{x}} \mathrm{Al}_{\mathrm{x}}\right) \mathrm{O}_{10}(\mathrm{OH})_{2}
$$$$
\mathrm{K}\left[\left(\mathrm{Mg}, \mathrm{Fe}^{2+}\right)\left(\mathrm{Fe}^{3+}, \mathrm{Al}, \mathrm{Ti}\right)\right](\mathrm{Si}, \mathrm{Al})_{4} \mathrm{O}_{10}(\mathrm{OH})_{2}
$$

dioctahedral

trioctahedral
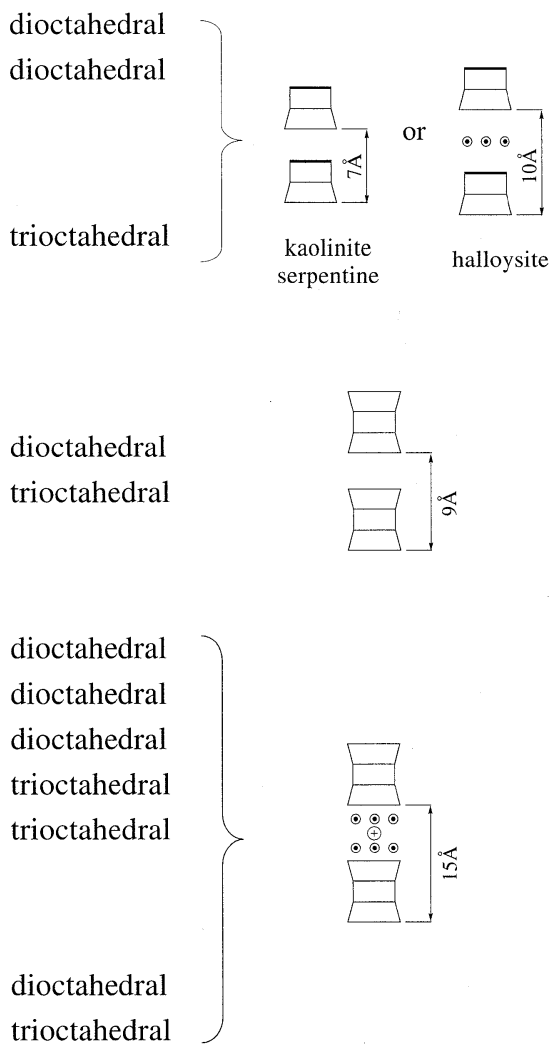

dioctahedral

dioctahedral

trioctahedral

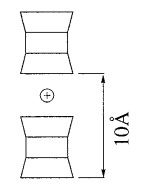

dioctahedral

trioctahedral

trioctahedral
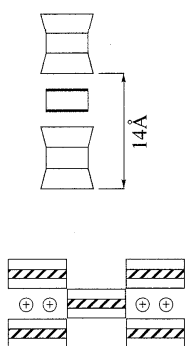

$0: 1$ (Anion-Exchange Clay)

LAYERED DOUBLE HYDROXIDE

hydrotalcite

$$
\begin{aligned}
& \mathrm{M}^{2+}{ }_{(\mathrm{x}+\mathrm{y}+2 \mathrm{z}) / 2}\left(\mathrm{Mg}_{8-\mathrm{y}-\mathrm{z}} \mathrm{M}^{3+}{ }_{\mathrm{y}} \square_{\mathrm{z}}\right)\left(\mathrm{Si}_{12-\mathrm{x}} \mathrm{M}^{3+}{ }_{\mathrm{x}}\right) \mathrm{O}_{30}(\mathrm{OH})_{4}\left(\mathrm{OH}_{2}\right)_{4} \bullet 8 \mathrm{H}_{2} \mathrm{O} \\
& \mathrm{M}^{2+}{ }_{(\mathrm{x}-\mathrm{y}+2 \mathrm{z}) / 2}\left(\mathrm{Mg}_{5-\mathrm{y}-\mathrm{z}} \mathrm{M}^{3+}{ }_{\mathrm{y}} \square_{\mathrm{z}}\right)\left(\mathrm{Si}_{8-\mathrm{x}} \mathrm{M}^{3+}{ }_{\mathrm{x}}\right) \mathrm{O}_{20}(\mathrm{OH})_{2}\left(\mathrm{OH}_{2}\right)_{4} \cdot 4 \mathrm{H}_{2} \mathrm{O}
\end{aligned}
$$

a) $\mathrm{M}_{\mathrm{int}}$ : intercalated metal cations, $\mathrm{M}_{\mathrm{oct}}$ : cations occupying octahedral position, $\mathrm{M}_{\mathrm{tetra}}$ : cations occupying tetrahedral position.

b) $\square$ = tetrahedral sheet, $\square$ = octah edral sheet, $\quad-=\mathrm{OH}$ surface, $\odot=\mathrm{H}_{2} \mathrm{O}, \quad \oplus, \ominus \quad$ =intercalated ions 
intercalated between the clay layers. For example, montmorillonite is capable of adsorbing guest cations according to the magnitude of the cation exchange capacity (CEC), which is expressed as the milliequivalents of the anionic sites per unit gram of the clay. The efficiencies of the intercalations are dependent on the type of clays and guest molecules. ${ }^{6}$ Adsorption on clays is accomplished by adding equimolar ionic substrates into aqueous colloidal clay solutions and applying sonication with an ultrasound mixer, which sometimes result in precipitations. In most cases, the intercalated clay colloids can be homogeneously dispersed in hydrophobic solvents such as benzene, chloroform and dichloromethane. Moreover, non-ionic materials may also be intercalated within the clay interlayers. ${ }^{7,8}$

\subsection{Anion-Exchange Clay (Layered Double hydroxide; LDH)}

In contrast to the cationic exchange clays mentioned above, layered double hydroxide of a brucite-type structure (abbreviated as LDH) include exchangeable negative ions, causing the effective adsorption of negatively charged guest molecules, and leading to what is called anion exchange clays. Similar to the case of montmorillonite, LDH accommodates guest anions according to the magnitude of its anion exchange capacity (AEC), expressed as milliequivalents of the cationic sites per unit gram of the clay. ${ }^{9}$ The properties of LDH are also shown in Table 1. A representative LDH clay is hydrotalcite, which is naturally produced and consists only of octahedral unit cell sheets of magnesium hydroxide accompanied by differing amounts of aluminum (normally one-fourth of $\operatorname{Mg}(\mathrm{OH})_{2}$ ), as depicted in Figure 2. Divalent anions such as $\mathrm{CO}_{2}{ }^{2-}$ intercalated in $\mathrm{LDH}$ have difficulty being exchanged with foreign anions. Therefore, it can be dehydrated to magnesium aluminium oxide by heating at $450{ }^{\circ} \mathrm{C}$, losing the carbon dioxide. Then, it can be rapidly rehydrated, adsorbing various anions and reconstructing the hydrotalcite structure. ${ }^{10,11}$ The simple structure of this LDH enables the artificial synthesis of various kinds of $\mathrm{LDH}$ with lattice metal ions such as $\mathrm{Zn}-\mathrm{Al}, \mathrm{Co}-\mathrm{Al}$, and $\mathrm{Fe}-\mathrm{Al}$, and can be applied to catalytic systems. ${ }^{12}$

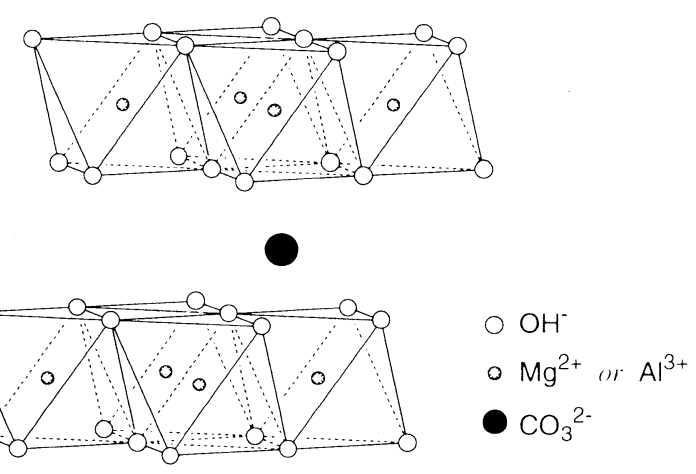

Figure 2. Structure of Mg-Al LDH (Hydrotalcite).

\section{Adsorption and Aggregation of Organic Molecules in Layered Hosts}

Among a variety of clay minerals, smectites and vermiculites can efficiently adsorb various ionic and polar organic compounds within its interlayers. The intercalation is quite easily accomplished by magnetic stirring of the clay-dis- persed aqueous solution with an appropriate amount of guest ions dissolved in water or sometimes added directly as a powder. Such intercalation can be utilized as a probe for the identification of 2:1 type clay minerals. ${ }^{5 b, 13}$ Due to ionic exchange with the exchangeable alkali ions, generally, more than $95 \%$ of the guest ions can be incorporated on the basis of the cation-exchange capacity (CEC) of the clay. ${ }^{14}$ Also, non-ionic guests with large dipole moments, such as ketones and nitriles, can be adsorbed to the exchangeable metallic ions within the layers according to their coordination with the ionic sites in the interlayers. ${ }^{\text {5a }}$ Mica and kaolinite have only a low ability to exchange ions since strong interactions between clay layers arise due to the high charge densities. However, appropriate treatment enables the intercalation reactions to proceed also in these clay minerals.

The anisotropic nature of intercalated guest molecules has been observed since the beginning of clay chemistry. The adsorption property in clays permits the mutual interaction of the incorporated guests which form self-assembling molecular aggregates due to the two-dimensional layer surface in contrast to silica colloidal surfaces. ${ }^{15}$ The efficiency of the self-assembly interaction depends on the structure of the clay minerals and guest organic compounds, the kind and amount of exchangeable metallic ions, and the amount of intercalated water in the interlayers. Detailed information on the high dimensional structure of the guest molecules has been obtained by various spectroscopic analytical methods such as $\mathrm{X}$-ray diffraction, neutron scattering or high-resolution electron microscopy, nuclear magnetic resonance (NMR), ${ }^{16}$ electron spin resonance (ESR), ${ }^{17}$ as well as polarized spectroscopies which are able to clarify the orientations of the guests within the layers. ${ }^{18}$ In addition, Messbauer spectroscopic analysis and ESCA have been employed to further elucidate the structures. ${ }^{19}$

The pioneering work of Weiss has shown that a long alkyl chain containing ammonium ions is intercalated as an antiparallel oriented monolayer between the layers, which could then be changed to a bilayer by the dispersion of higher alcohol, similar to the case of LB film. ${ }^{20}$ Moreover, the bis (long chained alkyl) ammonium ions themselves form extremely stable bilayer film aggregates when intercalated in montmorillonite. This can be deduced from comparisons between the molecular lengths and basal spacings estimated by the $\mathrm{X}$-ray diffraction spectra. Laponite, a synthetic hectorite, forms mono- or bilayers of cetyltrimethylammonium chloride (CTAC), depending on the amounts of CTAC. ${ }^{6}$ That is, the addition of an equivalent amount of CTAC gives rise to a monolayer, while the addition of excess amounts of CTAC yields bilayers. In contrast, the reorganization of the adsorbed surfactants is assumed at a given adsorption degree on the clay surface which is considered to be hemimicelle or admicelle. The size of these detergent aggregates can be estimated by a pyrene fluorescence quenching method, so that, for the cetyltrimethylammonium ion, the aggregation number was determined to be $24 .^{21}$

$\mathrm{LDH}$ is able to incorporate carboxylate anions equal to their anion exchange capacity. In most cases the intercalation occurs at moderate temperature $\left(\mathrm{ca} .70{ }^{\circ} \mathrm{C}\right.$ ) and the incorporated anions give rise to an alternatively arranged monolayer structure. However, it has been found that higher aliphatic carboxylate ions can be intercalated up to $250 \%$ AEC, yield- 
ing bilayers in the interlayers. Such bilayered structures can also be formed at low temperatures of around $5{ }^{\circ} \mathrm{C}$ even in the absence of excess amounts of aliphatic carboxylates. In this case, alternatively stacked layers consisting of vacantand bilayers of the guest carboxylate are formed. However, the so-called second stage of the LDH clays cannot be observed in the case of the intercalation of excess amounts of guest molecules. ${ }^{22,23}$

The geometry of the intercalated organic guest molecules has been investigated by polarized light using spectroscopy with UV, visible or infrared light as the light source. Specifically, electric linear dichromism (ELD) is a useful technique in the measurement of the geometry of the species in suspended solutions. The orientation of ionic disk-like clay particles in a suspended solution is electrically governed, and therefore, enables the determination of the steric alignment of the particles under the influence of an electrostatic field. ${ }^{24}$ Originally, O'Konski et al. reported the polarization effect of the absorbance of guest molecules intercalated in clay particles suspended in aqueous solution. ${ }^{25}$ Since then, there have been a series of related studies on ELD analyses of clay-organic hybrid colloids to uncover the definite conformation of the incorporated organic guests. ${ }^{26,27}$ For example, stilbenecarboxylate ions incorporated in LDH clay interlayers were shown to have a definite orientation at around $39.4^{\circ}$ from the clay layer surface. ${ }^{28}$ Moreover, it has been reported that the electro-fluorescence polarization technique can be applied to the measurement of the geometry of intercalated dye molecules under an applied electric field. ${ }^{29}$

\section{Stereoselective Photocycloadditions in Layered Hosts}

\subsection{Photocyclodimerization of Olefins in Clay}

Photochemical [2+2] cyclodimerizations are a useful probe in revealing the alignment of olefin molecules, organized or not, in heterogeneous fields. Various kinds of organized media have been employed for such cyclodimerizations. For example, it has been reported that the solid-state photocyclodimerization of cinnamic acids form the corresponding photodimers which possess specific stereochemical structures templated by the aggregated structures of the monomers in crystal. ${ }^{30}$

Clay interlayers are also quite useful as electrostatic fields for photochemical cyclodimerizations. Thus, stilbazolium ions (1) intercalated on montmorillonite interlayers were shown to undergo a selective cyclodimerization to yield a $s y n$-head to tail (HT) dimer. ${ }^{31,32,33}$ (eq. 1) The high regioselectivity for the syn-HT dimer clearly indicates the predominant anti-parallel alignment of $\mathbf{1}$. That is, the stilbazolium ions are alternatively adsorbed on the upper and lower layer surfaces of the clay, as is depicted in Figure 3. In fact, it has been shown that clay minerals may form a bilayer film of intercalated alkylammonium ions. Interestingly, only an excimer fluorescence could be observed from the clay-intercalated stilbazolium ions for a wide coverage of 0.1 to $20 \%$. This indicates that a strong excimer fluorescence, even with a $0.1 \%$ coverage, is realized only by the formation of a cluster of olefin molecules. ${ }^{20}$ The cluster formation is supported by the fact that the preferential formation of $s y n-\mathrm{HT}$ dimer can always be observed regardless of the extent of coverage, but the adsorbed stilbazolium cations are realized in the state of an adsorption equilibrium with the external bulk solution.
However, the clusters of intercalated stilbazolium ions were found to be dissociated by the coadsorption of alkylammonium ions with a molecular length longer than that of the olefin. Coadsorption of long-chain alkyl ammonium ions effectively quenched the photocyclodimerization of $\mathbf{1}$ as well as the excimer fluorescence. ${ }^{32}$

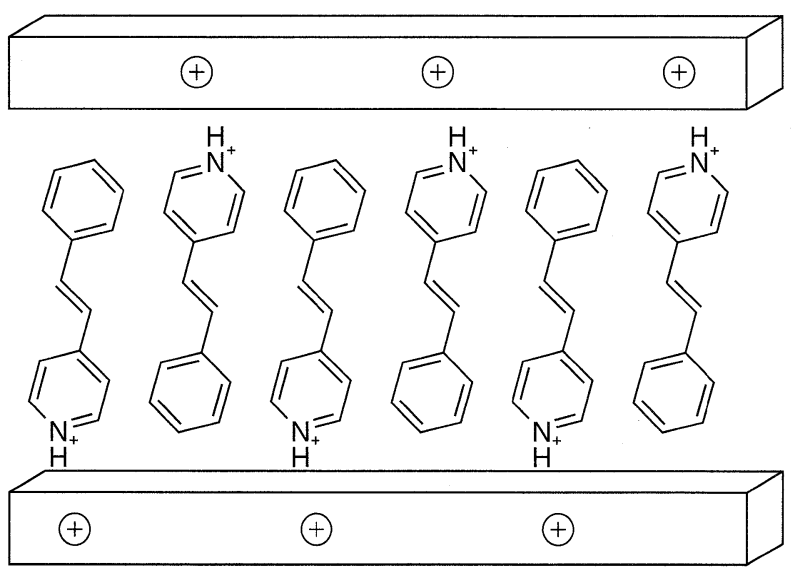

Figure 3. A schematic representation of 1a packing in the interlayers of saponite clay.

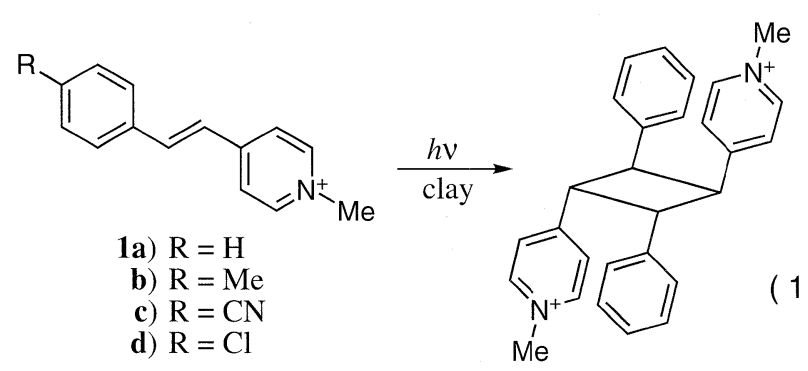

Nonionic but polar ketones, cyclohexenones (2) and cyclopentenones (3) are adsorbed on montmorillonite, though the intercalation efficiency is rather low and undergoes a photocyclodimerization which forms an anti-head-tohead $(\mathrm{HH})$ dimer.(eq. 2, 3) ${ }^{34}$<smiles>[2H]C1=CC(=O)CC([2H])C1</smiles>

2a) $\mathrm{R}=\mathrm{H}$

b) $\mathrm{R}=\mathrm{Me}$

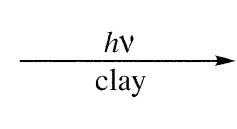<smiles>[R]C1CC([R7])C2([R])CC([R7])CC(=O)C2C1</smiles>

anti-HH<smiles>[R]C1CC([R])C2([R])CC([R7])CC(=O)C2C1</smiles>

anti-HH<smiles>[R]C1CC(=O)C2C(C1)C([R])C1C(=O)CC([R])CC12</smiles>

anti-HT

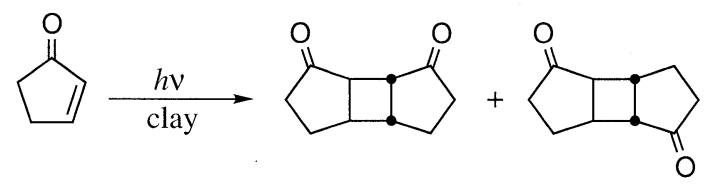


Table 2 summarizes the effect of saponite clay, in comparison with other additives, on the photodimerization of the cyclic enones. The product ratio of $\mathrm{HH}$ - to HT-dimers in photolysis of 2a intercalated on saponite clay layers was as high as 17 (run 1), in stark contrast to the reaction in bulk solution (run 8) which proceeded only about one-tenth as fast as that on clay layers and predominantly affording antiHT dimer. Meanwhile hydrotalcite, an anion exchange clay, could not improve the reactivity because no intercalation of the olefin occurred. Although olefin 3 can be adsorbed in the micropores on silica gel, the resulting stereoselectivity was quite low (see run 6). Moreover, similar low stereoselectivity is seen in activated alumina.

Table 2. Photodemerization of cyclic enons on clays

\begin{tabular}{|c|c|c|c|c|c|}
\hline \multirow{2}{*}{ enons } & \multirow{2}{*}{ clays } & \multicolumn{3}{|c|}{ dimer yields $(\%)$} & \multirow{2}{*}{$\mathrm{HH} / \mathrm{HT}^{\mathrm{a}}$} \\
\hline & & anti-HH & syn-HH & anti-HT & \\
\hline \multirow[t]{4}{*}{$\mathbf{2 a}$} & saponite & 27 & 0 & 2 & $97 / 7$ \\
\hline & montmorillonite & 1.1 & 0 & 1.6 & $42 / 58$ \\
\hline & hydrotalcite & 0.9 & 0 & 1.2 & $42 / 58$ \\
\hline & ${ }^{b}$ & $<0.05$ & 0 & 0.2 & $18 / 82$ \\
\hline \multirow[t]{4}{*}{$2 \mathbf{b}$} & saponite & 3.6 & 3.5 & 1.1 & $87 / 13$ \\
\hline & montmorillonite & 2.9 & 2.9 & 0.9 & $86 / 14$ \\
\hline & hydrotalcite & 0.6 & 0.5 & 0.4 & $73 / 27$ \\
\hline & ${ }^{b}$ & $<0.02$ & $<0.02$ & 0.1 & $28 / 72$ \\
\hline \multirow[t]{3}{*}{3} & saponite & 1 & 0 & 4 & $20 / 80$ \\
\hline & hydrotalcite & 0.2 & 0 & 2.0 & $9 / 91$ \\
\hline & $\longrightarrow^{\mathrm{b}}$ & 22 & 0 & 54 & $29 / 71$ \\
\hline
\end{tabular}

${ }^{\mathrm{a}}($ anti-HH $+\operatorname{syn}-\mathrm{HH}) /$ anti-HT. ${ }^{\mathrm{b}}$ Without clay.

It is now apparent that saponite clay accelerates the photodimerization of cyclohexenones and the regiochemistry is completely opposite to the case of bulk benzene solutions. It has been reported that polar solvents favor the formation of HT dimers over $\mathrm{HH}$ dimers. ${ }^{35}$ The present high selectivity for the $\mathrm{HH}$ dimers might be partly, but not wholly, due to the polarity of the clay interlayers. This is because the polar surface of $\mathrm{SiO}_{2}$ adsorbed the enone but was ineffective for selective photodimerization. Thus, the interlayer surfaces of the cation-exchange clays are significant for the present $\mathrm{HH}$-selective photodimerization of enones. It is known that ketones and nitriles can be intercalated by coordinating the cations of the clay interlayers and they have a much more ordered and regular alignment than those on silica gel or Vycor glass surfaces. ${ }^{36}$

\subsection{Photocyclodimerization of Anionic Olefins in LDH}

Hydrotalcite, i.e. $\mathrm{Mg}-\mathrm{Al} \mathrm{LDH}$, is able to adsorb anionically charged olefins such as cinnamate $(E-\mathbf{4})$ or stilbenecarboxylate anions $(E-\mathbf{5})$ into its interlayers.(eq. 4,5$)$ The adsorption equilibria are dependent on the kinds of anions adsorbed. For example, ca. $37 \%$ of cinnamate $(E-\mathbf{4 a})$ was intercalated from an equivalent mixture of the clay and cinnamate anions; however, stilbenecarboxylate $(E-\mathbf{5 a})$ was adsorbed quantitatively. The intercalated carboxylates were photodimerized mainly or exclusively to yield the corresponding syn-HH dimers (6) from $E-\mathbf{4}$. Noteworthy here is no occurrence of $E-Z$ photochemical isomerization, which is in contrast to the reaction in a homogeneous solution. The selective formation of $s y n-\mathrm{HH}$ dimers also indicates the close packing of the olefin molecules. However, stilbenecarboxylates $(E-5)$ gave rise to a mixture of $s y n-\mathrm{HH}(7)$ and HT dimers $(\mathbf{8})$. The product distributions in the photolyses of $E-\mathbf{4}$ and $E-\mathbf{5}$ have been summarized in Table $3{ }^{37,38}$

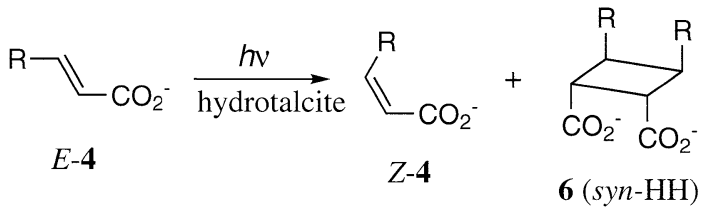<smiles>[R]C(=[W])c1ccc(-c2ccccc2)cc1</smiles><smiles></smiles><smiles>[X]c1ccc(/C=C/c2ccc(C(=O)O[Na])cc2)cc1</smiles>

c) $\mathrm{X}=\mathrm{Cl}$

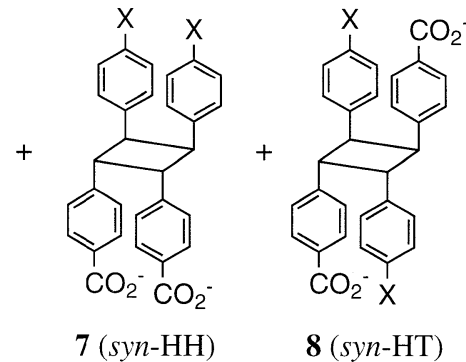

Table 3. Photocyclodimerization of unsaturated carboxylates in the presenze of hydrotalcite clays

\begin{tabular}{lrrccc}
\hline $\begin{array}{c}\text { unsaturated } \\
\text { carboxylate } \\
(\mathrm{mM})\end{array}$ & clay & \multicolumn{5}{c}{ product yields (\%) } \\
\cline { 4 - 6 }$(\mathrm{mM})$ & cis & syn-HH & syn-HT & anti-HH \\
\hline 4a (10) & 18.8 & 53 & 46 & 0.7 & 0.4 \\
4b (5) & 7.6 & 3 & 97 & - & - \\
4c $(10)$ & 18.8 & 25 & 75 & - & - \\
$\mathbf{5 a}(5)$ & 7.6 & 6 & 65 & 27 & - \\
$\mathbf{5 b}(5)$ & 7.6 & 1 & 87 & 6 & - \\
$\mathbf{5 d}(5)$ & 7.6 & 3 & 95 & 2 & - \\
$\mathbf{4 a}(5)$ & 0 & 100 & - & - & 0.4 \\
$\mathbf{4 b}(5)$ & 0 & 96 & 4 & - & - \\
4c $(5)$ & 0 & 100 & - & - & - \\
$\mathbf{5 a}(5)$ & 0 & 66 & 5 & 25 & 4 \\
$\mathbf{5 a}(50)$ & 0 & 65 & 10 & 20 & 5 \\
$\mathbf{5 b}(4)$ & 0 & 96 & 0.7 & 4 & - \\
\hline & & & & &
\end{tabular}


Models for the intercalation of guest molecules could be reasoned from $\mathrm{X}$-ray diffraction analysis of the intercalated clay powders. The gallery heights of the olefin-intercalated LDH were calculated by subtracting the $\mathrm{Mg}(\mathrm{OH})_{2}$ sheet thickness of $4.77 \AA$ from the 003 basal spacings. Since the gallery height for the intercalated $\mathrm{Cl}^{-}$was $2.9 \AA$, the intercalation of the carboxylates $E \mathbf{- 4}$ or $E \mathbf{- 5}$ elongated the interlayer distance up to $14-19 \AA$, values close to or slightly larger than the length of the guest anions. This led to the conclusion that intercalated carboxylate anions may, in principle, be oriented in anti-parallel fashion since the anion-exchange sites are distributed on both sides of the clay interlayers. Such antiparallel packing would seem to be plausible since the guest carboxylate ions are anchored at the anion-exchange sites distributed over the interlayer sheets every $5.2 \AA$, which is enough to allow such $a n t i-$ parallel packing to occur. Figure 4 illustrates the anti-parallel molecular packing of $E-\mathbf{4}$ and $E-5$. Also, the assumption that the homogeneous scattered $\mathrm{Al}$ atoms in the $\mathrm{Mg}(\mathrm{OH})_{2}$ sheets could be verified by $X$-ray analysis.

Anti-parallel packing, however, does not always straightforwardly explain the stereochemistry of the cyclodimers

(a)

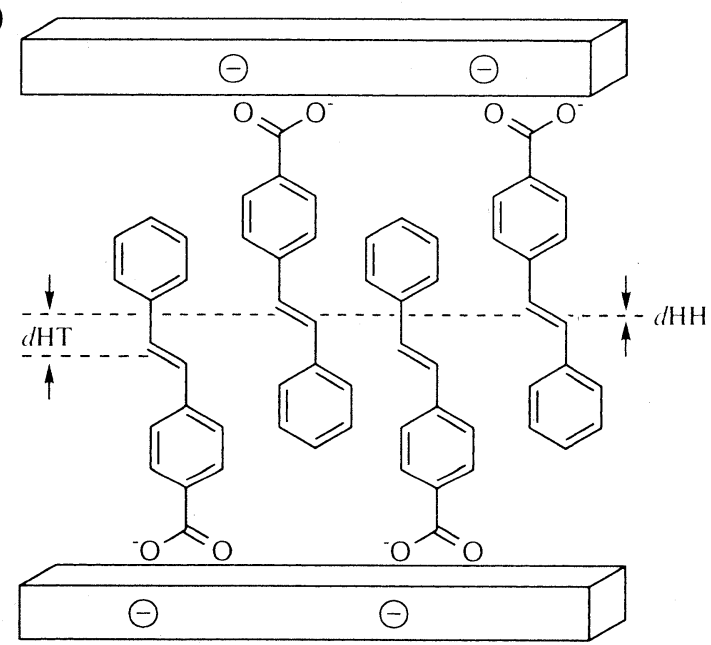

(b)

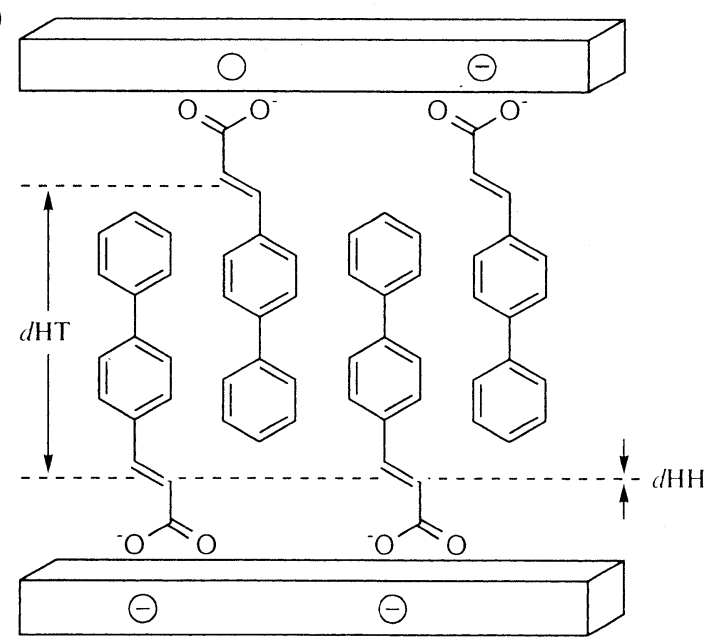

Figure 4. Molecular packings of carboxylates in hydrotalcite clay: (a) stilbenecarboxylate (5a) and (b) $p$-phenylcinnamate ions $(\mathbf{4 b})$. formed. Cinnamates $(E-4)$ yielded almost exclusively head-to-head dimers (6), but the stilbenecarboxylates $(E-5)$ led to significant amounts of head-to-tail dimers (8) in addition to a head-to-head isomers (7) (Table 3). The formation of two isomers is well understood by the anti-parallel packing since one olefinic molecule is surrounded by both a parallel olefin on the same surface and by an anti-parallel chain on the other surface.

As shown in Figure 4, the selective formation of head-to-head dimers from the cinnamates can be explained by the importance of the intermolecular distances of the two double bonds of the adjacent carboxylates. The two double bonds for the parallel (i.e., head-to-head) pairing are separated by $5.2 \AA$, and located at the same height from the layer surfaces (i.e., dHH is equal to zero), but those for the antiparallel (i.e., head-to-tail) orientation are quite variable, depending on the molecular structures and the gallery heights. The estimated value (i.e., dHT) for $p$-phenylcinnamate (4b) along the molecular axis is over $7 \AA$ while that for stilbenecarboxylates (5a) is below $4 \AA$. The estimated distance of over $7 \AA$ for the present case of cinnamates is too far to interact for an effective cyclodimerization to proceed, while the lateral distance of the $\mathrm{HH}$ pairing molecules on the same surfaces remains constant at $5.2 \AA$, a value sufficient for dimerization. This led to the observed selective formation of head-to-head dimers. In contrast, the dimerization of intercalated stilbenecarboxylates $(E-5)$ should be possible for either the head-to-head or the head-to-tail orientation. These results suggest that unsaturated carboxylates are intercalated in anti-parallel orientation and their photodimerizations are controlled by the distance of the double bonds from the ionic sites of the interlayers.

The effect of the coadsorbates is interesting in elucidating another feature of the photodimerization of intercalated olefinic carboxylates. The addition of sodium $p$-phenethylbenzoate (9), a photochemically inactive coadsorbate, significantly affected the product distribution in the photolysis of stilbenecarboxylate $(E-\mathbf{5 a})$ (Figure 5). The ratio of $s y n-\mathrm{HH}$ (7) and $s y n-\mathrm{HT}$ dimers (8) decreased gradually from 2.4 to unity as the amount of the coadsorbate $\mathbf{9}$ increased. At the same time, the major reaction pathway shifted from [2+2] cyclodimerization to cis-trans isomerization, suggesting an increase in the amount of isolated unsaturated carboxylate molecules. 'I'he dilution effect on the ratio of $s y n-\mathrm{HH}$ to syn-HT can be tentatively understood by the following speculations: The $1: 1$ product ratio of $s y n-\mathrm{HH}$ and $s y n-\mathrm{HT}$ in high dilutions may reflect the predominant $1: 1$ pairing of the stilbenecarboxylate molecules and the equal probability of parallel and anti-parallel pairings. The product ratio of 2.4 in the absence of coadsorbate (9) indicates the slightly more preferable formation of head-to-head dimers when a stilbenecarboxylate molecule is surrounded by both neighboring parallel and anti-parallel molecules.

In addition, the ion exchange capacity of clay plays an important factor in the determination of the regioselectivity

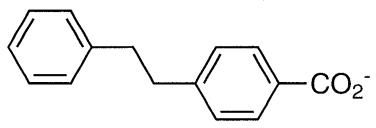




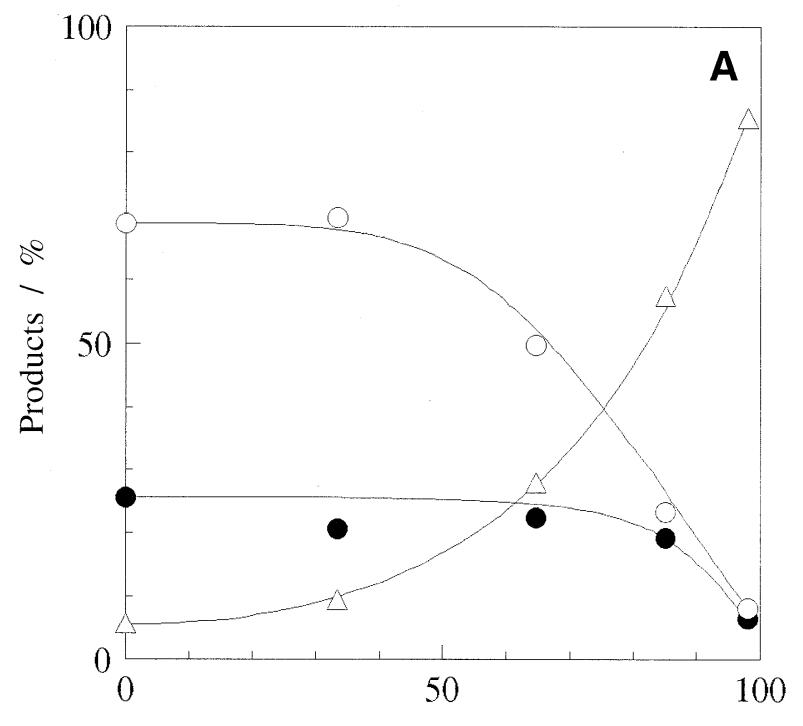

Coadsorbate (9) / \%

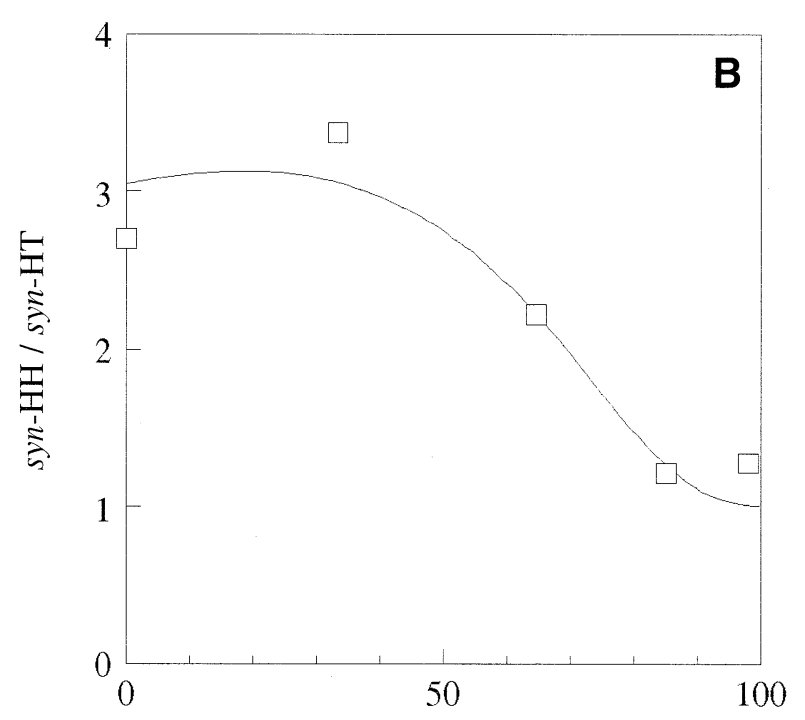

Coadsorbate (9) / \%

Figure 5. Effect of coadsorption of 9 on (A) the product distribution of photocyclodimerization of $E-\mathbf{5 a}$ in clay; $-\bigcirc$-: syn-HT (8a); - -: syn-HH (7a); - $\triangle^{-}$: cis (Z-5a), and on (B) the stereoselectivity of the cyclodimers.

of the cyclodimers. For example, cinnamate $(E-\mathbf{4 a})$ and stilbenecarboxylate ions $(E-5 a)$ lead to a mixture of $s y n-\mathrm{HH}$, ant $i-\mathrm{HH}$ and $s y n-\mathrm{HT}$ photocyclodimers together with the corresponding $c i s$-isomers with a substantial increase in $s y n-\mathrm{HH}$ and, at the same time, decrease in $c i s-$ isomers when the cation exchange capacity (AEC) of the LDH clay increases. ${ }^{39}$ This is reasonable considering that the lateral distance between the adjacent olefin increases when the AEC, which induces the possibility of a $\mathrm{HH}$ pairing to form a $\mathrm{HH}$-isomer, is increased.

It has been reported that 4-benzoylbenzoate $(\mathbf{1 0 a}-\mathbf{f})$ sensitizes the cyclodimerization of the cinnamates $(E-\mathbf{4 a})$ intercalated in hydrotalcite clay interlayers. (eq. 6) ${ }^{40}$ The easy formation and high stereoselectivity of the cyclodimer causes the sensitization to operate by an exciplex formation mechanism between the excited singlet $\mathbf{1 0}^{* 1}$ and $\mathbf{4 a}$, though the possibility of a triplet sensitization cannot be disregarded. The effects of the concentration and heavy atom substituents of the sensitizer can thus be understood by the sensitization mechanism through exciplex formations.

$$
\text { E-5a } \frac{10 / h v+Z \text {-5a }}{\text { hydrotalcite }} \begin{array}{ll}
\text { a) } \mathrm{X}=\mathrm{H} & \text { d) } \mathrm{X}=\mathrm{Br} \\
\text { b) } \mathrm{X}=\mathrm{F} & \text { e) } \mathrm{X}=\mathrm{I} \\
\text { c) } \mathrm{X}=\mathrm{Cl} & \text { f) } \mathrm{X}=\mathrm{OMe}
\end{array}
$$

\section{$4.3[2+2]$ Cross Addition}

The cycloaddition between different molecules in clay can exhibit unique properties depending on the extent of the mixing of the substrate with the reactant. In contrast to solution photochemistry, the adsorbed molecules are not generally scattered on the surface and tend to group themselves as a molecular structure. Hence, homogeneous mixing is needed in obtaining cross-bred products.

Photochemical cross-additions of olefins are enhanced by intercalation in clays upon UV irradiation. An equimolar mixture of $p-\mathrm{Me}(\mathbf{1 b})$ and $p-\mathrm{CN}$ substituted stilbazolium ions (1c) gave rise to formation of one cross-bred and two homodimers in a statistical ratio of $2: 1: 1$ in the $[2+2]$ photocyclodimerization. (eq. 7) However, when a mixture of clay hybrids of $\mathbf{1 b}$ and $\mathbf{1 c}$, after independently adsorbed on saponite, was irradiated in aqueous dispersion, the crossed dimers decreased with a decrease in the intercalation degree from $100 \%$ to $20 \%$. Especially, with a $20 \%$ coverage, no formation of the crossed dimers could be observed at all, implying that the migration of the olefins among clay particles is dependent on the intercalation degree. ${ }^{41}$

$\mathbf{1 b}+\mathbf{1 c} \underset{\text { clay }}{\stackrel{h v}{\longrightarrow}}$

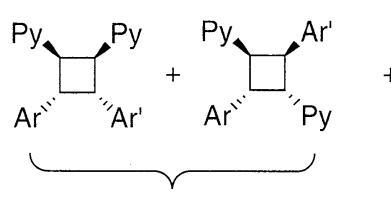

cross dimers

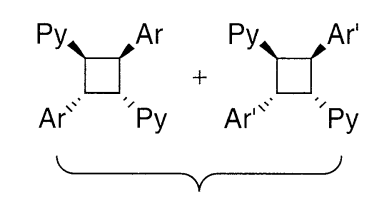

homo dimers

$$
\mathrm{Ar}=p-\mathrm{C}_{6} \mathrm{H}_{4} \mathrm{CH}_{3}, \quad \mathrm{Ar} r^{\prime}=p-\mathrm{C}_{6} \mathrm{H}_{4} \mathrm{CN}
$$

When the excited 4-benzoylbenzoate (10a) reacted with stilbene-4-carboxylate (5a) in hydrotalcite clay, two oxetanes yielded stereoselectively; $c i s-\mathrm{HH}(\mathbf{1 1 a})$ and $c i s-\mathrm{HT}(\mathbf{1 1 b})$ in a ratio of around $10: 1$. (eq. 8$)^{42}$ Similar to the cyclodimerization of stilbenecarboxylate, the stereochemistry of the oxetanes can be understood by its molecular arrangement within the LDH interlayers. The oxetanes of benzophenone with stilbene could not be observed in the usual triplet photochemistry in a solution. Such unexpected oxetane formation can be understood by the favorable packing and orientation of the carbonyl and olefin bonds in the clay layers, as shown 
in Figure 6. Moreover, the regular alignment in the interlayer spaces enables the formation of an exciplex state for these molecules.

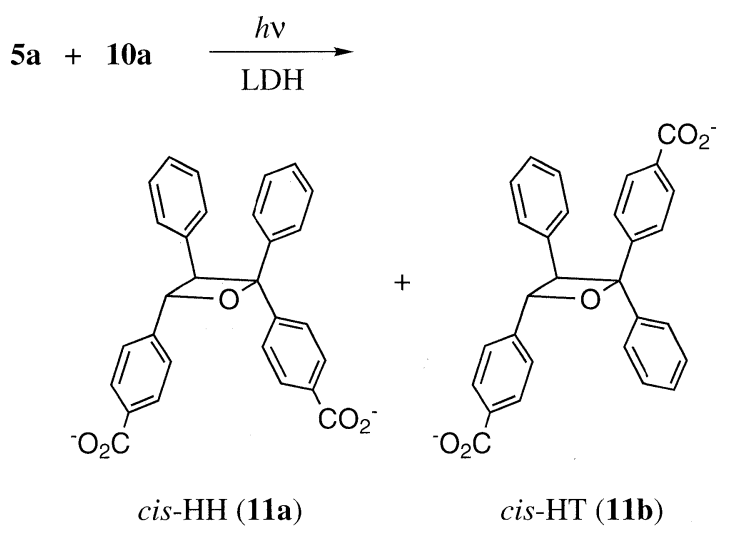

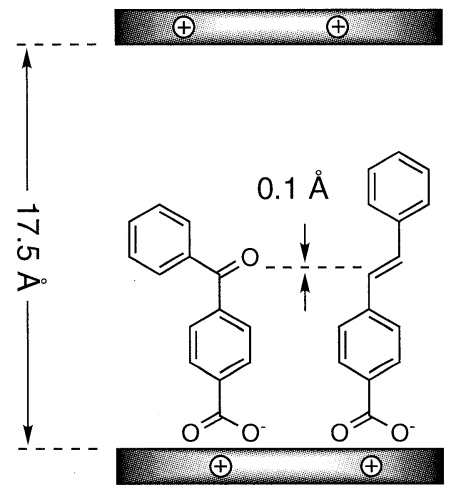

(a)

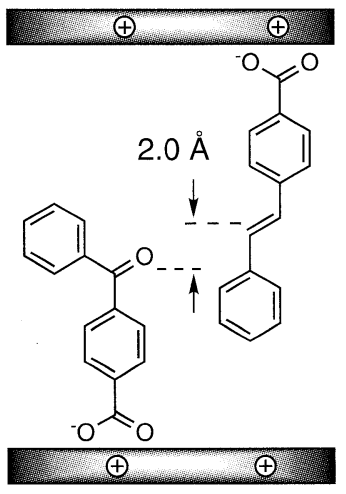

(b)
Figure 6. Schematic drawing of HH (a) and HT (b) packings of $\mathbf{5 a}$ and 10a in hydrotalcite interlayers.

\section{Photopolymerizations in LDH Interlayers}

The intercalation of polymers into clay minerals is also an important area of research since hybridization can produce functional materials endowed with unique physical properties such as moisture adsorption. In order to prepare polymer-clay hybrids, the polymerization of clay-intercalated prepolymers has been studied besides the intercalation of polymers. For example, it has been reported that acrylonitrile monomer intercalated montmorillonite clay could be polymerized to form poly(acrylonitrile). The clay-intercalated polymers have been noted to improve heat-resistance properties in comparison with clay-free polyacrylonitrile. ${ }^{43 a, b}$ Moreover, further heat treatment of the hybrid formed graphite-like planar carbon. ${ }^{43 c, d}$ Nylon-clay hybrids $(\mathrm{NCH})$, nylon-6 resins dispersing homogeneously several weight percent nanoparticle clay, have been developed for use in automobile parts as highly heat-resistant reinforced plastics. ${ }^{44}$

\subsection{Photopolymerization of Diacetylenes}

Highly functional polymers can also be formed within clay interlayers. Polyacetylenes and polydiacatylenes have been attractive owing to electric conductivity and nonlinear optical properties. 12,14-Eicosadienoic acid (12) can be incorporated in $\mathrm{LDH}$ to form a bilayer membrane structure of the hybrid (12/LDH). UV or $\gamma$-ray irradiation of the resulting $12 / \mathrm{LDH}$ hybrid induced the formation of polydiacetylene, while the color of the composite turned red $\left(\lambda_{\max }=590 \mathrm{~nm}\right)$ and blue $\left(\lambda_{\max }=640 \mathrm{~nm}\right)$. In the case of a low intercalation degree, polymerization does not proceed efficiently for the hybrid to be colorized, since the molecular density in the hybrid is low. In the case of $200 \%$ AEC coverage of $\mathbf{1 2}$ in hydrotalcite clay, however, excessive diacetylene loading 12/LDH hybrids, on $\mathrm{UV}$ or $\gamma$-ray irradiation, resulted in change in coloration from red to blue as shown in Figure $7 .{ }^{45}$ Completely polymerized diacetylene adsorbing hybrids are expected to have good electronic conductivity in view of the fact that blue-colored polydiacetylene is known to be an efficient electric conductor.

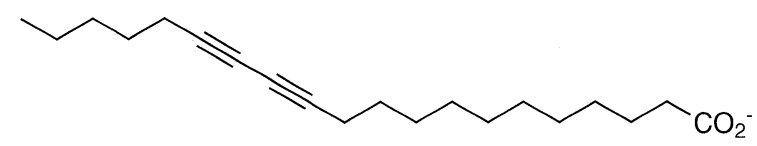

12

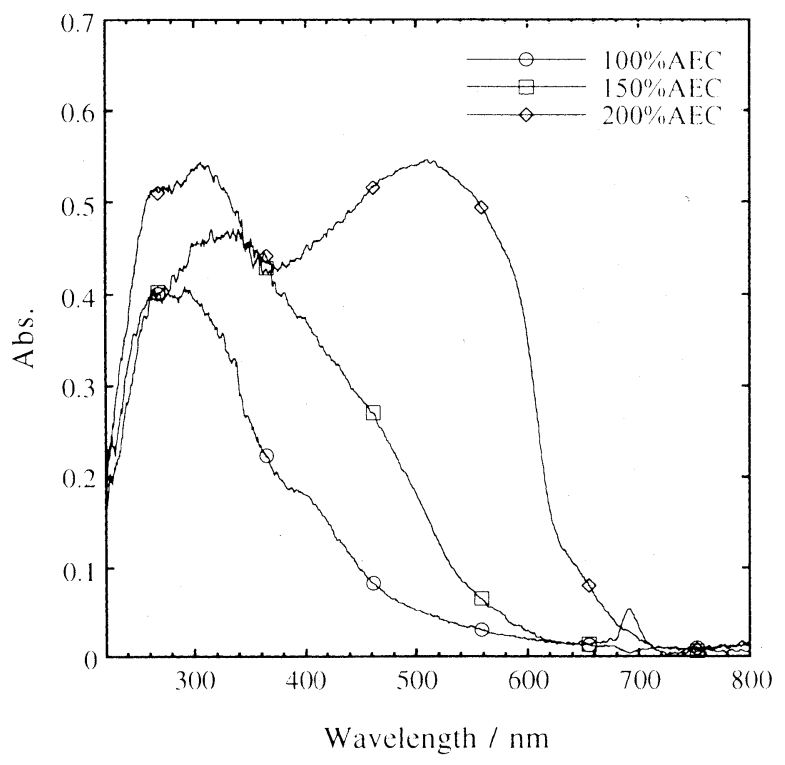

Figure 7. Absorption spectra of polydiacetylene/LDH hybrids; the intercalation degrees of $\mathbf{1 2}$ are 100,150 and $200 \%$ on the basis of AEC.

\subsection{Stereoselective Photopolymerization in LDH}

The interlayer spaces of clay minerals are stereoselective photoreaction fields, especially for intermolecular photoreactions. Thus, stereoselective photopolymerization, i.e., stereoregularity control in the clay interlayers is also an attractive subject. Photochemical polymerizations of intercalated 4-vinylbenzoate (13) and $p$-(or $\mathrm{m}-$ )phenylenediacrylate ion $\left(p-\left(\right.\right.$ or $\left.\left.m^{-}\right) 14\right)$ were investigated in the presence of $\mathrm{Mg}-\mathrm{Al}$ $\mathrm{LDH}$, hydrotalcite. UV irradiation of $\mathrm{LDH}$-intercalated $\mathbf{1 3}$ gives rise to the [2+2] cyclodimerization in a similar manner as cinnamates and stilbenecarboxylates. In the presence of benzoylbenzoate (10a), radical polymerization occurs to form polyvinylbenzoate with $10-10^{3}$ as a degree of the polymerization. (eq.9) ${ }^{46}$

The stereoregularity of the polystyrene was investigated by NMR analysis and is discussed in relation to the molecular alignment of the aggregates within the clay interlayers. It 
could be assumed by ${ }^{13} \mathrm{C}$ and ${ }^{1} \mathrm{H}-\mathrm{NMR}$ analyses that polystyrene conformation was favorable for isotactic rather than atactic. In contrast to the case of vinylbenzoate (13), the photolysis of the intercalated $p^{-}$, or $m^{-14}$ resulted in the formation of $[2+2]$ cycloadditive oligomers, the polymerization degrees of which were up to ten at most. (eq. 10) Dianionic molecules such as $p \mathbf{- 1 4}$ showed interesting intercalation behavior in comparison with monoanions, that is, just negatively charged bicarboxylate ions were estimated to occupy three anion exchange sites of the hydrotalcite based on a single molecule of $p-\mathbf{1 4}$, though the reason is not clear. Powder $\mathrm{X}$-ray diffraction analysis showed that the molecular aggregation site could be remarkably changed by drying the clay composite in vacuum, showing that the photopolymerization is suppressed. ${ }^{46}$<smiles>O=C([O-])C=Cc1ccc(C=CC(=O)[O-])cc1</smiles>

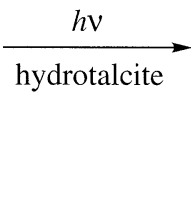

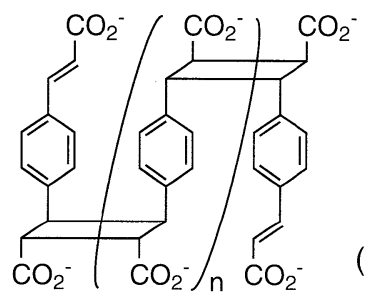

\section{4}

$(m-$ or $p-)$

\section{Photoreaction of Clay-Intercalated Aromatic Ketones}

Ketones are also fundamental and important compounds in the field of photochemistry. Electronically excited ketones usually react in the triplet state, causing various kinds of reactions, such as energy transfer, hydrogen abstraction, $\mathrm{C}-\mathrm{C}$ cleavage and so on. These reaction pathways sometimes compete and thus the complicated mixtures of the photoproducts are formed. Restriction of conformational and migratory movement of the molecules by intercalation suggests a possibility to control the reaction courses and to obtain the selected products. For this purpose, photoreactions of aromatic ketones have been investigated in the presence of clay minerals.

\subsection{The Norish Type I and Type II reactions}

Photolysis of ketocarboxylates $\mathbf{1 5}$ possessing a valerophenone structure resulted in the formation of eliminated and cyclized products caused by Norrish type II reaction in the presence of hydrotalcite clay in variable yields depending on the length of alkyl chains $(n) .{ }^{47}$ (eq.11) The cyclization product was decreased with increasing $\mathrm{n}$ and became negligible when $n>6$. This is in marked contrast to the photolysis of $\mathbf{1 5}$ in aqueous solution. Norrish type II reaction is known to be initiated by $\gamma$-hydrogen abstraction through a six-membered cyclic transition state. The formation of the Norrish type II products may indicate that the ketocarboxylate ions possess conformational flexibility even in the hydrotalcite interlayers. However, cyclization requires much larger reaction volume since the resulting cyclobutanol is bulky. The aggregation stretches the long alkyl chain owing to the increase of hydrophobicity in the interlayer spaces, and thus prevents formation of the cyclized products.

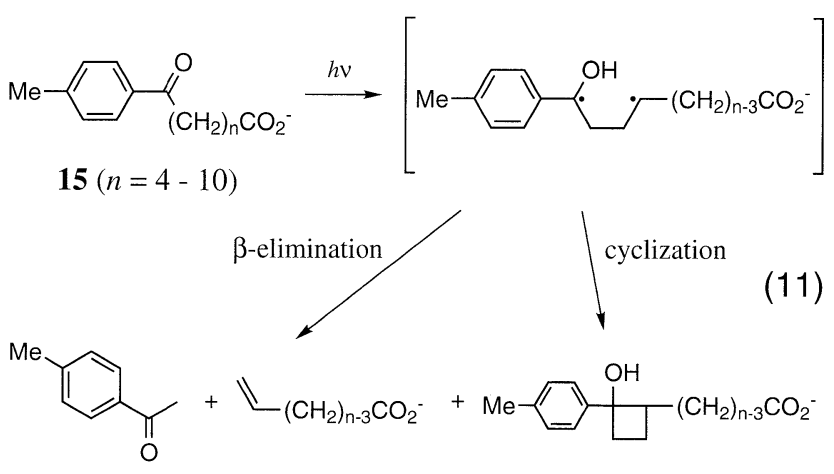

\subsection{Bimolecular Hydrogen Abstraction}

Bimolecular hydrogen abstractions are also investigated in the clay interlayers. Photoirradiation of a mixture of 4-benzoylbenzoate (10a) and aliphatic carboxylates resulted in the formation of cross-bred adducts. (Figure 8) Analyzing the position of the carbon atom in the alkyl chain where the reaction occurred, it was revealed that $\mathrm{C}_{4}$ and $\mathrm{C}_{5}$ are selective in the photolysis of clay-intercalated hybrids as well as $\mathrm{C}_{\mathrm{n}-1}$ (a carbon next to the terminal). This positional selectivity can be explained by the alignment of benzoylbenzoate and aliphatic carboxylates. That is, $\mathrm{C}_{4}$ and $\mathrm{C}_{5}$ are close to photoexcited carbonyl oxygen in the $\mathrm{HH}$ pairing of $\mathbf{1 0 a}$ and aliphatic carboxylate, and $\mathrm{C}_{\mathrm{n}-1}$ is close to it in the $\mathrm{HT}$ pairing. ${ }^{48}$

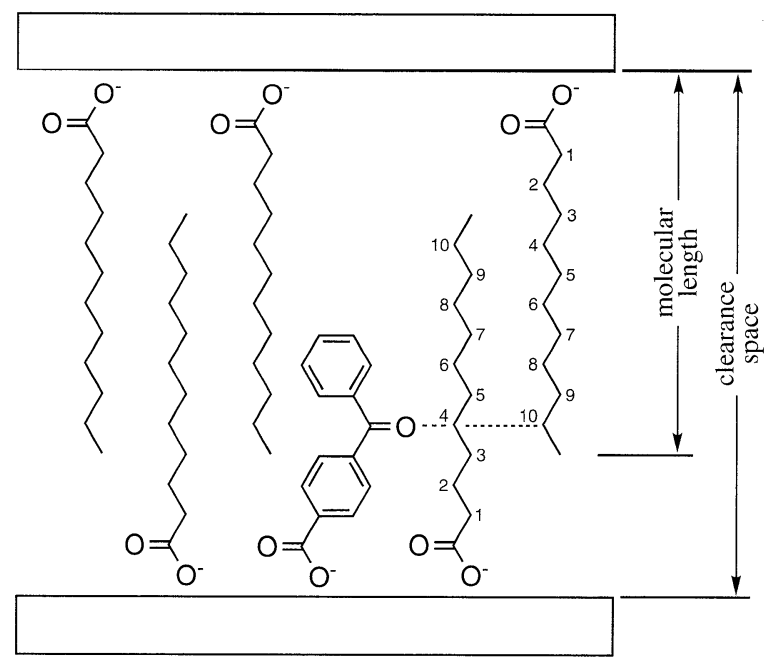

Figure 8. Schematic molecular packing of co-intercalated mixture of aliphatid carboxylate and 4-benzoylbenzoate (10a).

\subsection{Enantioselective Photopinacolization in LDH}

By utilizing the hydrogen abstraction of benzoylbenzoate, chiral induction in the clay interlayer was studied. Induction of molecular chirality is a most interesting and important 
process, but a difficult area in organic synthesis. Although clay minerals, in principle, do not possess any chiral source in their chemical structures, control of the chirality can be realized by introducing optically active molecules into their interlayer reaction fields. Intercalated benzoylbenzoate (10a) in an LDH interlayer abstracts hydrogen photochemically from the co-intercalated benzhydrolcarboxylate (16), forming mesoand $d l$-benzopinacol (17) in $c a .1: 1$ ratio. By using clay intercalated optically active $d-$ or $l \mathbf{- 1 6}$ for the photopinacolization, either $l$ - or $d$-benzopinacol is selectively formed. (eq12) The optical yields of the pinacolization are observed to be $60 \%$ e.e. at the initial stage of the photopinacolization. The pinacol formation proceeds by way of $\alpha$-hydrogen abstraction from benzhydrol by the excited triplet benzophenone followed by the recombination of the resulting two ketyl radicals. In solution, these two ketyl radicals can move freely in the solvent cage so as to escape out of the cage, resulting in the loss of enantioselectivity. However, when the pinacolization of 10a and $\mathbf{1 6}$ is carried out in the confined LDH interlayer spaces, an excited 10a may abstract the hydrogen of 16 more preferably from one side of the molecular plane, since they are well-concentrated and assembled. The preferable formation of $d^{-}$or $l$-pinacol is rational in that the rotation and diffusion of the resulting ketyl radicals are suppressed by the upper and lower layers of the $\mathrm{LDH}^{49}$

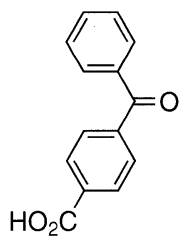

$10 \mathrm{a}$

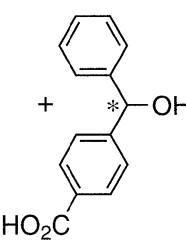

16

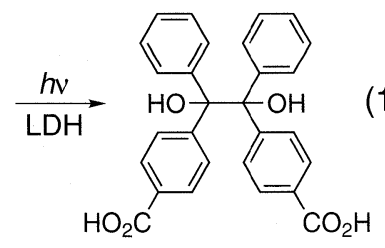

$d$-, $l$ - and meso-17

\section{Summary}

Various kinds of photochemical reactions of clay-organic intercalation compounds were described in this article in order to elucidate their characteristic reaction circumstances caused by the confined space sandwiched by inorganic nano size layer matrices. In the photochemical reaction of intercalation compounds, their unique molecular arrangement and aggregation properties can control not only the photochemical reaction course of the guest molecules but also the stereochemistry of the products. Fundamental studies into the design of such sophisticated reaction fields will provide promising and valuable applications for new photochemical and photobiological systems and processes.

\section{References}

1) Thomas, J. K. Acc. Chem. Res. 1988, 21, 275.

2) Thomas, J. K. Chem. Rev. 1993, 93, 301.

3) (a) Thomas, J. K. Report, ARO-20647. 11-CH, Order No. ADA186099 1987, pp. 23. (b) Thomas, J. K. Report, ARO-16951. 7 $\mathrm{CH}$, Order NO. AD-A133421 1983, pp. 15.

4) Ogawa, M.; Kuroda, K. Chem. Rev. 1995, 95, 399.

5) (a) Theng, K. G. The Chemistry of Clay-Organic Reactions; Adam Hilger, London, 1974. (b) Grim, R. E. Clay Mineralogy; McGraw-Hill, New York, 1953.

6) Barrer, R. M. Clays Clay Miner. 1989, 37, 385.

7) Thomas, J. K. Acc. Chem. Res. 1988, 21, 275

8) Pinnavaia, T. J. Sci. 1983, 220, 365.
9) Miyata, S. Gypsum \& Lime 1983, 187, 47.

10) Sato, T.; Wakabayashi, T.; Shimada, M. I\&EC PRODUCT RESEARCH \& DEVELOPMENT 1986, 25, 89.

11) Kanezaki, E. A. J. Mater, Sci. Lett. 1998, 17, 371

12) Miyata, S. Clays Clay Miner. 1980, $28,50$.

13) Swartzen-Allen, S. L.; Matijevic, E. Chem. Rev. 1974, 74, 385.

14) (a) Sissoko, I.; Iyagba, E.; Sahai, T.; Biloen, R. J. Solid. State Chem. 1985, 60, 283. (b) Thevenot, R.; Szymanski, R.; Chaumette, P. Clays Caly Miner. 1989, 37, 396.

15) Synder, L. R.; Ward, J. W. J. Phys. Chem. 1966, 70, 3941.

16) O'Hare, D. Chem. Soc. Rev. 1992, 19.

17) Kim, R. M.; Pillon, J. E.; Burwell, D. A.; Groves, J. T.; Thompsom, M. E. Inorg. Chem. 1993, 32, 4509.

18) (a) Yamanaka, S.; Kanamaru, F.; Koizumi, M. J. Phys. Chem. 1975, 79, 1285. (b) Fredericq, E.; Houssier, C. Electric Dichroism and Electric Birefringence; Clarendon Press, Oxford, 1973. (c) Stoylov, S. P. Colloid Electrooptics: Theory, Dichroism and Applications; Academic Press, New York, 1991. (d) Yamagishi, A.; Taniguchi, M.; Takahashi, M.; Asada, C.; Matsushita, N.; Sato, H. J. Chem. Phys. 1994, 98, 7555.

19) Firipiat, J. J. Advanced Tecniques for Clay Mineral Analysis; Elesevier, Amsterdam, 1982.

20) (a) Weiss, A. Chem. Ber. 1958, 91, 487. (b) Weiss, A. Angew. Chem. 1963, 75, 113. (c) Lagaly, G. Angew. Chem., Int. Ed. Egnl. 1976, 15, 575

21) Kuniyma, B.; Viaene, K.; Khalil, M. H.; Schoonheydt, R. A.; Crutzen, M.; DeSchtyver, F. C. Langmuir 1990, 6, 482.

22) Fogg, A.; Dunn, J. S.; O’Hare, D. Chem. Mater. 1998, 10, 356.

23 ) (a) Kanoh, T.; Shichi, T.; Takagi, K. Chem. Lett. 1999, 117. (b) Itoh, T.; Shichi, T.; Takagi, K. Langmuir in press.

24) (a) O'Konski, C. T.; Zimm, B. H. Sci. 1950, 111, 113. (b) Shah, M. J. J. Phys. Chem. 1963, 67, 2215. (c) Yoshida, M.; Hayashi, M.; Kikuchi, K.; Watanabe, H. Dynamic Behavior of Macromolecules, Colloids, Liquid Crystals and Biological Systems by Optical and Electrooptical Methods; Hirokawa, Tokyo, 1989 (pp.349). (d) Sasai, R.; Ikuta, N.; Yamaoka, K. J. Phys. Chem. 1996, 100, 17266.

25) O'Konski, C. T.; Bergmann, K. J. J. Phys. Chem. 1962, 37, 1573.

26) Yamagishi, A.; Nakamura, Y.; Taniguchi, M.; Kaneyoshi, M.; Watanabe, H. Dynamic Behavior of Macromolecules, Colloids, Liquid Crystals and Biological Systems by Optical and Electrooptical Methods; Hirokawa, Tokyo, 1989 (pp. 331).

27) (a) Taniguchi, M.; Kaneyoshi, M.; Nakamura, A.; Yamagishi, A.; Iwamoto, T. J. Phys. Chem. 1990, 94, 5869. (b) Taniguchi, M.; Yamagishi, A.; Iwamoto, T. Inorg. Chem. 1991, 30, 2462. (c) Yamagishi, A.; Taniguchi, M.; Takahashi, M.; Asada, C.; Matsushita, N.; Sato, H. J. Phys. Chem. 1994, 7555. (d) Chernia, Z.; Gill, D.; Yariv, S. Langmuir 1994, 10, 3988.

28) Sasai, R.; Shin'ya, N.; Shichi, T.; Takagi, K.; Gekko, K. Langmuir 1999, 15, 413.

29) Windsor, S. A.; Tinker, M. H. Colloids Surfaces A 1999, 148, 61.

30) Ramamurthy, V.; Venkatesan, V. Chem. Rev. 1987, 87, 433.

31) (a) Zawadzki, M. E.; Ellis, A. B. J. Org. Chem. 1983, 48, 3156. (b) Gessner, F.; Olea, A.; Lobaugh, J. H.; Johnstone, L. J.; Scaiano, J. C. J. Org. Chem. 1989, 54, 259.

32) Usami, H.; Takagi, K.; Sawaki, Y. Bull. Chem. Soc. Jpn. 1991, $64,3395$.

33) Usami, H.; Takagi, K.; Sawaki, Y. J. Chem. Soc. Perkin Trans. 2 1990, 1723.

34) Usami, H.; Takagi, K.; Sawaki, Y. Chem. Lett. 1992, 1405.

35) Valentine, D.; Turro, N. J.; Hammond, G. S. J. Am. Chem. Soc. $1964,86,5202$.

36) (a) Hrnjez, B. J.; Mehta, A. J.; Fox, M. A.; Johnston, K. P. J. Am. Chem. Soc. 1989, 111, 2662. (b) Fox, M. A.; Cardona, R.; Ranada, A. C. J. Org. Chem. 1985, 50, 5016

37) Takagi, K.; Usami, H.; Shichi, T.; Sawaki, Y. Mol. Cryst. Liquid Cryst. 1992, 218, 109

38) Takagi, K.; Shichi, T.; Usami, H.; Sawaki, Y. J. Am. Chem. Soc. 1993, 115, 4339.

39) Shichi, T.; Takagi, K.; Sawaki, Y. J. Chem. Soc., Chem. Commun. 1996, 2027.

40) Shichi, T.; Takagi, K.; Sawaki, Y. Clay Sci. 1999, 10, 503.

41) (a) Usami, H.; Takagi, K.; Sawaki, Y. J. Chem. Soc. Faraday Trans. 1992, 88, 77. (b) Takagi, K.; Usami, H.; Shichi, T.; Sawaki, Y. Mol. Cryst. Liquid Cryst. 1992, 218, 109.

42) Shichi, T.; Takagi, K.; Sawaki, Y. Chem. Lett. 1996, 781.

43) (a) Glaveti, O. L.; Polak, L. S. Neftekhim. 1963, 3, 905. (b) Glaveti, O. L.; Polak, L. S. Neftekhim. 1964, 4, 77. (c) Kyotani, 
T.; Sonobe, N.; Tomita, A. Nature 1988, 331, 331. (d) Sonobe, N.; Kyotani, T.; Hishiyama, Y.; Shiraishi, M.; Tomita, A. J. Phys. Chem. 1988, 92, 7029 .

44) (a) Usuki, A.; Kojima, Y.; Kawasumi, M.; Okada, A.; Fukushima, Y.; Kurauchi, T.; Kamigaito, O. J. Mater. Res. 1993, 8 1179. (b) Usuki, A.; Koiwai, A.; Kojima, Y.; Kawasumi, M.; Okada, A.; Kurauchi, T.; Kamigaito, O. J. Apply. Poly. Sci. 1995, 55,1193 .

45) Itoh, T.; Shichi, T.; Takagi, K. unpublished data.

46) Shichi, T.; Yamashita, S.; Takagi, K. Supramolecular Sci. 1998, 5, 303 .

47) Takagi, K.; Harata, E.; Shichi, T.; Sawaki, Y. Photochem. Photobiol. A, Chem. 1997, 105, 47.

48） Takagi, K.; Saito, N.; Shichi, T.; Sawaki, Y. Chem. Lett. 1999, 275.

49) Shichi, T.; Yasuda, N.; Minamikawa, Y.; Yamada, N.; Takagi, K.; unpublished data.

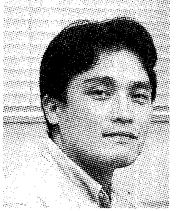

Tetsuya Shichi is an assistant professor in the Department of Crystalline Materials Science of Nagoya University. He graduated from the Department of Applied Chemistry of Nagoya University in 1991 and received his Ph.D. in 1997. He then joined Prof. K. Takagi's research group. His research interests are in the photochemistry of stereochemically controlled clay-intercalated compounds and the design of photofunctional materials utilizing organic-inoganic layered compounds. (tel:

, e-mail:

Katsuhiko Takagi is a professor of chemistry at the Department of Crystalline Materials Science of Nagoya University. He was born in 1942 in Nagoya and received his Bachelor and Doctorate degrees in engineering from Nagoya University under the supervision of Prof. Yoshiro Ogata. After graduation, his assistant and associate professorships were held under the guidance of Prof Yasuhiko Sawaki in the field of organic photochemistry. He joined the present faculty as a full professor in 1997. During his academic career, he studied under Prof. H. Hart at Michigan State University of East Lansing between 1978-1979, and with Prof. David G. Whitten at the University of Rochester in 1984. His recent research interests lie in the application of self-assembling organic-clay lamella films for the design of photofunctional materials. (tel: e-mail: 